\title{
Summer Literacy for Young Vulnerable Learners: A Study of Caregiver Involvement and Program Stability
}

\author{
Ashley Graham and John McNamara \\ Brock University \\ Jackie VanLankveld \\ Speech Services Niagara
}

\begin{abstract}
Emergent literacy programs for young children are significantly more effective when caregivers are integral components of program delivery. This is particularly important when designing programs for vulnerable children such as those with lower academic achievement due to learning and language disabilities, lower socioeconomic environments, or learning in a language other than their native language. Including caregivers in program delivery will impact not only the effectiveness of the program but also its stability. This exploratory study investigated the efficacy and stability of a summer family literacy program on the reading achievement of 14 four-year-old children completing their pre-kindergarten year. Children were assessed prior to, immediately proceeding, and 6 months following the summer program. The results of the study indicated that children demonstrated significant gains in all aspects of emergent literacy and furthermore, sustained these gains 6 months after the program.
\end{abstract}

Contextual variables, such as home literacy routines, shared reading, and provision of literacy materials, have been shown to be critical components of the effectiveness and sustainability of emergent literacy interventions (Dickinson \& McCabe, 2001). Research has indicated that literacy interventions generally are more effective and have a greater chance of being sustained when caregivers or family members are directly involved in the delivery of the intervention (Timmons, 2008). This is particularly true for vulnerable learners such as those requiring special educational needs, children from lower socioeconomic backgrounds, and children learning English as a second language. Heath (1982) pointed to the notion that variations in the quality and quantity of home literacy are associated with familial contextual variables such as socioeconomic status, marital status, and unemployment. The emotional and financial stress associated with socioeconomic and marital factors has been shown to significantly impact caregivers' mental well-being 
and capacity for effective parenting (Linver, Brooks-Gunn, \& Kohen, 2002).

This negative association between socioeconomic factors and emergent literacy achievement may be particularly problematic during summer months when children are not in school. Research has demonstrated that vulnerable learners are at risk for experiencing a summer learning loss - even more so than their typically-achieving peers (Cooper, Nye, Charlton, Lindsay, \& Greathouse, 1996). The findings of the Cooper et al. (1996) review indicated specifically that the summer learning loss phenomena may be particularly troublesome for less advantaged children including those requiring special educational needs, children from lower socioeconomic backgrounds, and children learning English as a second language. Specifically, it may be the reading or literacy-based skills that are most affected during the summer months. For instance, Kim (2006) found that on standardized measures of reading, children from middle to high socioeconomic backgrounds demonstrated some stability in reading achievement over the summer, whereas disadvantaged children showed significant losses.

Entwisle, Alexander, and Olson (2001) uncovered an interesting trend associated with summer learning loss and socioeconomic status (SES). In their Baltimore School Study, Entwisle et al. found that achievement levels of all children, regardless of their SES, increased during their Grade 1 school session. However, during the summer months between grades 1 and 2, when school was out of session, children from higher SES homes gained 15 points in their standardized reading achievement while children from lower SES homes lost 4 points in their standardized reading achievement. The results of the Entwisle et al. study indicate that children particularly vulnerable to summer learning loss may be those children from less advantaged homes. The implications of this study are that summer learning programs should be provided not only to children but also to families from lower SES backgrounds. Katsiyannis (1991) found similar results when studying summer learning loss and children with learning and behavioural difficulties. Specifically, Katsiyannis found that without continuous instruction throughout the summer months, many children with learning disabilities fall further behind their grade-level peers. In general, research illustrated clearly that the summer learning gap can be particularly problematic for vulnerable children; furthermore, literacy skills may be the area of achievement that is most affected. As such, it is imperative that stakeholders concerned with supporting young vulnerable learners strive to find ways to support these children, along with their families, during the summer months when vulnerable learners may be particularly at risk. The current study explores the stability of achievement gains attained in a summer family literacy program designed to support vulnerable readers at the end of their junior kindergarten year.

The current study is a follow-up to Graham, McNamara, and VanLankveld (2010) who studied the immediate impact of a summer family literacy program aimed at supporting young vulnerable readers. Graham et al. (2010) implemented a 5-week summer literacy program for 4and 5-year-old children who were considered at-risk for reading difficulties as indicated by their scores on the Test of Preschool Early Literacy (TOPEL; Lonigan, Wagner, Torgesen, \& Rashotte, 2007). In addition to qualifying for program participation based on emergent literacy scores, a criterion for participation was attendance of at least one primary caregiver. Children and caregivers attended the 5-week program twice weekly where caregivers would participate in a caregiver-only workshop learning strategies and tactics around teaching their children print and phonological awareness skills that they could implement in their homes. During each program session parents would also have time to practice their newly acquired skills with their children before leaving the program.

A battery of emergent literacy assessments was administered prior to and immediately af- 
ter the program. Results of the Graham et al. (2010) study indicated statistically and clinically significant gains in all measures of emergent print and phonological awareness and letter-sound understanding. The current study extended this research and measured the emergent literacy skills of the same children 6 months after the summer program was implemented. In other words, this study measured the stability of the achievement gains attained by participants in the Graham et al. study.

The intervention and assessment protocol adopted in this study is couched in the notion of emergent literacy. Emergent literacy may be defined as the developmental period of literacy between birth to the age of 6 (Teale \& Sulzby, 1986). In this study, the focus is on a number of specific skills associated with emergent literacy - that is, the development of phonological and print awareness. In addition to this, the current study focused on how caregivers can be instrumental in supporting their children in emergent literacy skill development. Although a number of studies have measured the long-term predictability of emergent literacy skills and their association with later reading outcomes, only a paucity of studies have measured the longer term stability of achievement gains initially produced by a literacy intervention. This may be due to the fact that most interventions are too brief or not explicit enough to create stable gains. O'Connor, Notari-Syverson, and Vadasy (1996) argued that brief literacy interventions (less than 15 weeks) are generally insufficient to produce achievement gains that can be sustained beyond the short-term.

However, it is argued here that by including caregivers as integral components of the intervention, the emergent literacy achievement gains experienced within the program may be sustained beyond the short-term period following the program. It is hypothesized that the caregivers, once provided with simple literacy tactics and strategies, will extend the summer literacy program into their homes creating a long-term home-based program of emergent literacy. In essence, including the caregivers as program participants will create a paradigmatic shift in the home-based literacy environment creating a more literacy-rich environment, allowing longerterm stability of program achievement gains.

The current study is also couched in the notion of family literacy. The notion of family literacy is becoming increasingly important as research has begun to elucidate the powerful effect that families can have on children's individual literacy achievement. As indicated previously, Timmons (2008) suggested that literacy interventions are most powerful when they include family involvement. Higher grades and test scores, more consistent completion of homework, and high self-efficacy are all linked with parental involvement (Desimone, 1999). However, Timmons indicated also that there are a number of challenges facing program designers. Timmons' review of family literacy programs found that in many cases, families were not authentic partners in the intervention process and it is suggested that program designers strive to create a unique, individual needs-based model for each participating family. Authentic caregiver partnership entails that intervention staff and parents are co-constructing and co-delivering the intervention program. In the current study, caregivers spend a significant amount of time working with program staff, engaging with their children in literacy activities aimed at improving their print and phonological awareness skills.

Timmons (2008) also indicated that many published family literacy programs did not use scientifically based research to inform the development and planning of the program and that there is a general lack of published research in the family literacy field. For these reasons, school boards, community agencies, and researchers have begun collaborating to look for creative ways to support vulnerable learners during the summer months. However, although all stakeholders 
are in agreement about the benefits of summer learning programs for vulnerable learners, there remain a number of questions about how to most effectively design and implement summer literacy programs.

Within the region of the current study, a number of community agencies have been working towards developing supports for vulnerable children during the summer months. For instance, Speech Services Niagara, a community agency serving approximately 1900 pre-school children demonstrating difficulties in their speech and/or language development, has recently implemented workshops in local libraries and early learning centres aimed at educating parents on how best to facilitate their child's emergent literacy skills. Further, in the spring of 2008, Speech Services Niagara completed five intensive family literacy program pilots that spanned over a 10 -week period. These programs have assisted the researchers with understanding the role of and pressures of the families in attending such a session as well as assisting with the development of the curriculum. More recently, many regional school board administrators and staff expressed interest in exploring ways to support vulnerable children during the summer months. These mutual interests led to the present partnership between the current research team, Speech Services Niagara, and a local school board with the common goal of designing, implementing, and assessing the efficacy of a summer literacy program aimed at supporting young vulnerable learners and their families from the local community.

\section{The Current Study}

The current study is a follow-up to Graham et al.'s (2010) project that investigated the impact of a summer family literacy program designed to support children who are struggling in their print and phonological awareness skills at the end of their junior kindergarten year. Results of the Graham et al. study indicated that the empirically-supported family literacy program, Learning Begins at Home: A Research-Based Family Literacy Program Curriculum (LBH; Doyle, Hipfner-Boucher, \& Pelletier, 2008), produced statistically significant gains in print and phonological awareness skills in vulnerable learners. The LBH program used in this study was implemented over a period of 5 weeks during the summer vacation months and a within group pre-post design was used. An important feature of this previous study was that the posttest was administered immediately after the summer program ended - thus measuring the direct impact of the summer program. The current study extends this research and measured the emergent literacy skills of the same children 6 months after the summer program was implemented. In other words, this study measured the stability of the achievement gains attained by participants in the Graham et al. study.

A number of literacy intervention studies have focused on direct instruction of literacy skills to at-risk readers. However, as indicated previously, literacy interventions may be enhanced significantly when caregivers are authentic partners in the program. As indicated previously, authentic caregiver involvement entails having caregivers integrally involved in the co-construction and delivery of their child's literacy program. In the broader sense, authentic partnerships would mean close, supportive relationships between educators and caregivers in the overall service delivery models with the school. However, to study caregiver involvement within the current study it was necessary to establish a research protocol whereby a requirement for participating in the summer literacy program is involvement of a child and one of his or her primary caregivers. The participating caregiver was integrally involved in the program, participating in workshop activities prior to and following hands-on literacy work with his or her child. 
By including primary caregivers as authentic partners, the research team hoped to encourage a paradigmatic shift in the family whereby literacy activities become routine within their household. Following this, it was important for the research team to utilize a literacy intervention program that included a family component and as such, the team adopted the LBH program (Doyle et al., 2008). The LBH program was designed to include caregivers as an integral part of the intervention process and the program also was designed to be flexibly adapted to suit the needs of each individual participating family.

\section{Method}

\section{Participants}

A total of 14 children ( 7 boys, 7 girls) along with at least one of their caregivers participated in this study. All participating children and families were living in Canada and attending one of six participating elementary schools. At the time of the first day of the program the mean age of children was 55 months. Study eligibility was determined using a two-step referral process. First, children were identified as having significant literacy needs based on their classroom teacher's analysis of their print and phonological awareness skill achievement. All participating children were attending junior kindergarten classrooms within a mid-sized school board from Southwestern Ontario, Canada. Each spring as part of the regular curriculum, the participating school board screens all junior kindergarten children on a number of observational measures including reading and literacy. As a result of this screening, a number of children are identified as having literacy-based needs. As a partner in the current study, the school board agreed to refer identified children for participation in the summer literacy program.

As a second step, children were assessed by a trained Speech and Language Pathologist, specializing in early literacy, to identify whether they met specific eligibility requirements for participation in the summer program. Specifically, children were assessed using the Test of Preschool Early Literacy (TOPEL; Lonigan et al., 2007). The TOPEL has been indicated as a significant predictor of later reading achievement. Children with overall Early Literacy Index scores below the $25^{\text {th }}$ percentile as indicated in the TOPEL technical data were eligible to participate in the study. Children were also assessed using a basic measure of letter identification and letter-sound identification - both measures indicated by research as being significant predictors of later reading achievement (Vervaeke, McNamara, \& Scissons, 2007). Both the TOPEL and the letter measures were also used as pretest and posttest measures.

A focus of the current study was vulnerable learners. As indicated previous, SES has been demonstrated to be associated with emotional and financial stress that may lead to less effective literacy environments. Although study criteria were based on lower academic achievement as indicated by the classroom teacher and the TOPEL and letter screening measures, socioeconomic data was collected from participating families. Participating families' average household income was $\$ 32,100$ per year. According to Statistics Canada (2007), the median national household income was $\$ 61,800$. Also, of the 14 participating children, 9 were living in single-caregiver homes and 5 were living in dual-caregiver homes. Regarding caregiver education, of the 14 participating caregivers, 3 did not complete high school, 9 completed Grade 12 without progressing to college/university, and 2 completed university degrees. The demographic data collected suggests that participating children may be considered as coming from lower SES backgrounds. 


\section{Procedures}

Children and their families then participated in a 5-week summer literacy program. The literacy program used in this study was an adaptation of the Learning Begins at Home: A Research-Based Family Literacy Program Curriculum (Doyle et al., 2008). This program was not specifically designed for summer use but more generally addresses the literacy needs of young children and furthermore includes caregivers as primary agents of program delivery. The LBH program focuses on three essential skills to emergent literacy: print awareness, phonological awareness, and letter-sound correspondence. The study's adaptation to the program included eight emergent literacy skill-based sessions focusing on specific components of emergent literacy. The sessions are described in detail in Table 1.

Although the program included eight different lessons, throughout the program the focus remained on children's development of print and phonological awareness. For instance, in Session Four (Talk with your Children) the focus was on developing oral vocabulary with a specific emphasis on words and letters with the intent to relate these to print and phonological awareness skills. Children and one of their primary caregivers attended sessions. The program was chosen by our research team as it is designed to be a culturally responsive family literacy program designed to support kindergarten-aged children and their caregivers. The LBH program combines focused literacy skill-building activities aimed at individual children with authentic parent/caregiver partnership activities aimed at bringing families together to address the literacy needs of their children.

The summer program took place for 5 weeks during the months of July and August where families attended twice weekly from 4-6pm. The LBH program consisted of one introductory session, eight 2-hour instructional sessions (described in Table 1), and one post-program session where the first set of posttest data was collected and families were debriefed on the program. In general, each 2-hour instructional section was sub-divided into three components. The first component (30 minutes) had children and caregivers working together with one teacher reviewing the objectives of the evening's lesson and collectively reading a story that was themed around the lesson's objectives.

Component two (45 minutes) had children and parents working separately. Children worked in small groups of three or four with a teacher supervising each group. Children worked on the skills related to each session (i.e., letter identification) but more so on the skills in which they required support. Parents worked in a separate room and participated in a workshop led by a Speech and Language Pathologist specializing in early literacy. The workshop was based on providing parents with activities, strategies, and tactics that they could use at home to support the individual literacy-based needs of their child.

Component three (30 minutes) had children and parents coming back together to practice and implement the strategies and tactics that parents had learned in their emergent literacy workshop. The third component ended with a story read to the entire group. Children and caregivers were provided with complimentary books and materials (i.e., markers, magnet letters, etc.) to support them in implementing at home the literacy strategies and tactics that they learned in the program. The program and materials were complimentary for all participants and each evening families were provided with supper. 
Table 1

Description of the Learning Begins at Home Instructional Sessions

\begin{tabular}{|c|c|c|}
\hline \multirow[t]{2}{*}{ Session Focus } & \multicolumn{2}{|c|}{ Instructional Session Description } \\
\hline & Children's Session & Parent's Session \\
\hline $\begin{array}{l}\text { Session 1: Introduc- } \\
\text { tion to program } \\
\text { Importance of reading }\end{array}$ & $\begin{array}{l}\text { Develop a sense of book awareness; con- } \\
\text { necting pictures to print; setting a reason for } \\
\text { reading. }\end{array}$ & $\begin{array}{l}\text { Overview of the program; caregivers' expecta- } \\
\text { tions; promoting literacy at home; explaining } \\
\text { dialogic reading. }\end{array}$ \\
\hline $\begin{array}{l}\text { Session 2: } \\
\text { Thinking about words } \\
\text { and sounds }\end{array}$ & $\begin{array}{l}\text { Focused on rhyming skills, segmenting syl- } \\
\text { lables, clapping syllables in their names, } \\
\text { initial letter recognition, blending simple } \\
\text { compound words. }\end{array}$ & $\begin{array}{l}\text { How to support children in listening to words } \\
\text { and sounds; teaching children how to rhyme, } \\
\text { segment syllables; games to promote chil- } \\
\text { dren's recognition of initial letters. }\end{array}$ \\
\hline $\begin{array}{l}\text { Session } 3 \text { : } \\
\text { Letter names and } \\
\text { sounds }\end{array}$ & $\begin{array}{l}\text { Scavenger hunt for letters, fishing for letters, } \\
\text { letters out of play-dough. Each activity had } \\
\text { children identify letters and say the corre- } \\
\text { sponding letter sound. }\end{array}$ & $\begin{array}{l}\text { The importance of letter and letter sound iden- } \\
\text { tification; the relationship between letter } \\
\text { knowledge and later reading; how to promote } \\
\text { letter knowledge at home through activities } \\
\text { such as letter bingo or concentration. }\end{array}$ \\
\hline $\begin{array}{l}\text { Session 4: } \\
\text { Talk to your child }\end{array}$ & $\begin{array}{l}\text { Children were encouraged to orally engage } \\
\text { with teachers through activities such as filling } \\
\text { in the last word of a rhyme or song. Children } \\
\text { followed oral instructions in how to make } \\
\text { puppets and play word-guessing games. }\end{array}$ & $\begin{array}{l}\text { Emphasized the link between children's oral } \\
\text { language development and literacy; focused } \\
\text { on strategies to develop oral language skills } \\
\text { such as asking questions about daily happen- } \\
\text { ings, telling stories, etc.; increasing oral } \\
\text { vocabulary by introducing new words into chil- } \\
\text { dren's existing repertoire. }\end{array}$ \\
\hline $\begin{array}{l}\text { Session 5: } \\
\text { Environmental print }\end{array}$ & $\begin{array}{l}\text { Focused on relationship between environ- } \\
\text { mental symbols (i.e., Stop sign) and word } \\
\text { meaning; searched classroom for environ- } \\
\text { mental print objects (i.e., Exit sign, fire alarm, } \\
\text { etc.); emphasized importance of reading } \\
\text { within real-world contexts. }\end{array}$ & $\begin{array}{l}\text { Focused on the purpose and importance of } \\
\text { environmental print; strategies on pointing out } \\
\text { environmental print within everyday activities; } \\
\text { introduced games and strategies using envi- } \\
\text { ronmental print (i.e., I-spy). }\end{array}$ \\
\hline $\begin{array}{l}\text { Session 6: } \\
\text { Read with your child }\end{array}$ & $\begin{array}{l}\text { Focused on book understanding; relevance } \\
\text { of books and reading with caregivers; vo- } \\
\text { cabulary development within the context of a } \\
\text { book. }\end{array}$ & $\begin{array}{l}\text { Why reading aloud to your child is important; } \\
\text { discussed book handling skills, reading with a } \\
\text { positive attitude; developing children's vocabu- } \\
\text { lary while reading; developing a sense of } \\
\text { narrative while reading; allowing children to } \\
\text { engage in oral reading (i.e., making predic- } \\
\text { tions, etc.); practiced effective dialogic } \\
\text { reading; introduced the idea of a "book walk." }\end{array}$ \\
\hline $\begin{array}{l}\text { Session 7: } \\
\text { Storytelling }\end{array}$ & $\begin{array}{l}\text { Children are read a story (i.e., Little Red Rid- } \\
\text { ing Hood); children illustrate favourite part of } \\
\text { story; retell the story; use simple oral sen- } \\
\text { tences to describe their illustration of the } \\
\text { story; make up their own story. }\end{array}$ & $\begin{array}{l}\text { Discussed importance of telling stories with } \\
\text { and without a book; strategies to encourage } \\
\text { discussion about everyday activities; impor- } \\
\text { tance of children telling stories about everyday } \\
\text { or special events; using prompts to encourage } \\
\text { children's storytelling. }\end{array}$ \\
\hline $\begin{array}{l}\text { Session 8: } \\
\text { Print awareness }\end{array}$ & $\begin{array}{l}\text { Drawing a picture and writing letters to par- } \\
\text { ents about the picture; focus on the } \\
\text { importance of print and writing in delivering } \\
\text { information or messages. }\end{array}$ & $\begin{array}{l}\text { Emphasized the importance of children devel- } \\
\text { oping print awareness and writing skills; the } \\
\text { importance of allowing children's creative writ- } \\
\text { ing and inventive spelling; strategies to } \\
\text { promote creative writing at home; using chil- } \\
\text { dren's picture-making and writing to illustrate a } \\
\text { story. }\end{array}$ \\
\hline $\begin{array}{l}\text { Session 9: } \\
\text { Exit session }\end{array}$ & $\begin{array}{l}\text { Children post-program emergent literacy } \\
\text { achievement was assessed with TOPEL and } \\
\text { letter knowledge measures. }\end{array}$ & $\begin{array}{l}\text { Parents were debriefed on the importance of } \\
\text { emergent literacy at home; a celebration of the } \\
\text { completion of the program. }\end{array}$ \\
\hline
\end{tabular}




\section{Measures}

Participating children were administered three sets of assessments: (a) a pretest assessment before the program began; (b) a posttest assessment on the last evening of the program (posttest I); and (c) a second posttest assessment approximately six months after the beginning of the program (posttest II). All three assessment sets included the TOPEL, lower letter name knowledge, and letter-sound correspondence, described below.

Test of Preschool Early Literacy (TOPEL). The TOPEL (Lonigan et al., 2007) is a theoretically sound instrument for identifying preschoolers who are at risk for literacy problems, therefore, allowing early intervention. The TOPEL provides valid and reliable raw and standard scores. The normative sample consists of 842 preschool-aged children ( 3 to 5 years). The current study used two TOPEL subtests - Print Knowledge and Phonological Awareness.

Print knowledge. This subtest has 36 items and measures alphabet knowledge and early knowledge about written language conventions and form. The child is asked to identify letters and written words, point to specific letters, name specific letters, identify letters associated with specific sounds, and say the sounds associated with specific letters. The reliability coefficient for the TOPEL Print Knowledge subtest for 4-year-old children was $\alpha=.96$.

Phonological awareness. This subtest has 27 items and measures word elision and blending abilities. The child is asked to say a word and then say what is left after dropping out specific sounds (elision) for the first 12 items. The child is asked to listen to separate sounds and combine them to form a word (blending) for the remaining 15 items. The reliability coefficient for the TOPEL Phonological Awareness subtest for 4-year-old children was $\alpha=.88$.

Lower letter name knowledge. Letter name association clearly taps into something of critical importance in early reading (Juel \& Meier, 1999). The major task of letter naming is mapping a visual symbol to a phonetic representation. Therefore, for this task children were shown all 26 lowercase letters of the English alphabet and asked to give the letter name. Students were scored as correct if they responded with the appropriate letter name.

Letter-sound correspondence. Letter-sound tasks require associating symbols with discrete sounds, which may be more challenging because they require isolating individual phonemes. Research has demonstrated that this skill has a significant causal effect on subsequent development of phonological skills (Juel \& Meier, 1999). For this task students were shown lowercase letters and asked to give the corresponding sound. If students responded with a letter's corresponding soft sound (e.g., /c/ as in race), they were prompted to think about another sound. The target sound was the hard consonant or short vowel sound. Students were scored as correct if they responded with the appropriate letter sound.

\section{Results}

Pretest and posttests I and II means and standard deviations are illustrated in Table 2. To measure the overall affect of the program across all three assessment points, a repeated-measures analysis of variance was computed for all measures of emergent literacy. For TOPEL Print Knowledge, an overall statistical effect was found, $F(2,12)=11.08, p<.005, \eta_{\mathrm{p}}{ }^{2}=.65$, indicating that across the course of the study, children experienced a statistically significant gain in their print knowledge. For TOPEL Phonological Awareness, an overall statistical effect was found, $F(2,12)=14.13, p<.001, \eta_{\mathrm{p}}{ }^{2}=.70$, indicating that children's phonological awareness skills 
Table 2

Means, Standard deviations, and Percentile Ranks for the TOPEL and Letter Knowledge Assessments at Three Assessment Points

\begin{tabular}{|c|c|c|c|c|c|c|c|c|c|c|}
\hline & \multicolumn{3}{|c|}{ Pretest } & \multicolumn{3}{|c|}{ Posttest I } & \multicolumn{3}{|c|}{ Posttest II } & \multirow[b]{2}{*}{$\mathrm{F}$} \\
\hline & $M$ & $S D$ & $\begin{array}{c}\text { \%ile } \\
\text { Rank }\end{array}$ & $M$ & $S D$ & $\begin{array}{c}\text { \%ile } \\
\text { Rank }\end{array}$ & $M$ & $S D$ & $\begin{array}{c}\text { \%ile } \\
\text { Rank }\end{array}$ & \\
\hline $\begin{array}{l}\text { TOPEL Print } \\
\text { Knowledge }\end{array}$ & 9.5 & 6.2 & 19 & 16.7 & 7.7 & 45 & 22.1 & 8.2 & 55 & $11.08^{*}$ \\
\hline $\begin{array}{l}\text { TOPEL } \\
\text { Phonological } \\
\text { Awareness }\end{array}$ & 12.4 & 5.8 & 19 & 17.3 & 5.8 & 58 & 20.5 & 4.8 & 61 & $14.13^{* *}$ \\
\hline Letter Names & 6.4 & 4.5 & $\mathrm{~N} / \mathrm{A}$ & 12.2 & 7.0 & $\mathrm{~N} / \mathrm{A}$ & 15.6 & 8.1 & $\mathrm{~N} / \mathrm{A}$ & $25.82^{\star *}$ \\
\hline Letter Sounds & 2.9 & 3.6 & N/A & 6.1 & 4.3 & N/A & 8.6 & 6.4 & $N / A$ & $14.91^{* *}$ \\
\hline
\end{tabular}

significantly increased over the entire duration of the study. A similar result was found for both measures of letter understanding. An overall statistically significant increase was found for lower letter name knowledge, $F(2,12)=25.82, p<.001, \eta_{\mathrm{p}}{ }^{2}=.81$, and for letter-sound correspondence, $F(2,12)=14.91, p<.001, \eta_{\mathrm{p}}{ }^{2}=.71$. These findings indicate that children's letter understanding significantly increased over the course of the study.

Following the statistically significant results of the general model, univariate analyses were computed to measure the specific effects between each of the assessment points. To explore the unique pretest and posttest I gains, paired sample $t$ tests were computed for all four measures of emergent literacy. Results indicated statistically significant gains for all measures between the start and the immediate completion of the program: TOPEL Print Knowledge, $t(14)=-3.16, p=$ .008 ; TOPEL Phonological Awareness, $t(14)=-4.35, p=.001$; lower letter name knowledge, $t(14)=-6.03, p<.001$; and letter-sound correspondence, $t(14)=-2.43, p=.030$.

Likewise, to measure the specific gains between posttest I and posttest II, paired sample $t$ tests were computed for all four measures of emergent literacy. Results indicated statistically significant gains for all measures between the immediate completion of the program and the 6 month follow-up assessments: TOPEL Print Knowledge, $t(14)=-2.84, p<.01$; TOPEL Phonological Awareness, $t(14)=-3.14, p<.008$; lower letter name knowledge, $t(14)=-5.01, p<.001$; and letter-sound correspondence, $t(14)=-3.48, p<.004$.

Although pretest, posttest I, and posttest II analyses revealed statistically significant increases for all measures, these analyses do not indicate whether the increases where clinically significant. In other words, it was important to ask whether the significant increases in scores for children reflect an increase whereby posttest scores were within achievement levels commensurate with typically-achieving 4-year-old children. This was particularly important in that a primary objective of the study was to investigate whether the gains found by Graham et al. (2010) were sustained as children began their next year of schooling.

To answer this question, pretest and posttest I and II mean scores for each TOPEL measure were compared against percentile rank scores as indicated by the TOPEL technical data. As indicated in Graham et al. (2010), clinically significant gains were found for pretest and posttest 
I scores. Specifically, for the TOPEL Print Knowledge measure at the pretest assessment point, participating children had a mean score of 9.5 (percentile rank score of 19); the corresponding posttest I mean score was 16.7 (percentile rank score of 45). These results indicated that for print awareness, in addition to a statistically significant gain, children demonstrated a clinically significant gain whereby their posttest scores were within the average range for typically developing 4.5-year-old children. A similar trend emerged for TOPEL Phonological Awareness. At the pretest assessment point, children had a Phonological Awareness mean score of 12.4 (percentile rank score of 19); the corresponding posttest I mean score was 17.3 (percentile rank score of 58). These results indicated that for phonological awareness, in addition to a statistically significant gain, children demonstrated a clinically significant gain whereby their posttest scores could be considered within the average range for typically developing 4.5-year-old children. Due to a lack of established benchmarks, clinically significant analyses were difficult to conduct for letter identification and letter-sound correspondence.

A similar set of analyses were computed for posttest I and posttest II measures. As indicated for the TOPEL Print Knowledge measure at the posttest I assessment point, participating children had a percentile rank score of 45. At the posttest II assessment point participants had a print knowledge mean score of 22.1 (percentile rank score of 55). This result suggests that children not only sustained the print knowledge achievement gains but also continued to improve relative to their age-matched peers. A similar result was found for TOPEL Phonological Awareness. At the posttest I assessment point, participating children had a percentile rank score of 58 . At the posttest II assessment point participants had a phonological awareness mean score of 20.5 (percentile rank score of 61). Complete percentile rank scores for all measures across the course of the study are illustrated in Table 2 .

Although percentile rank scores were not possible to establish for lower letter name knowledge and letter-sound correspondence, it is important to note the significant increase in mean letters known. Children increased their letter identification from 12.2 letters at posttest I to 15.6 letters at posttest II. Likewise, children increased their letter-sound correspondence from 6.1 letters at posttest I to 8.6 letters at posttest II.

\section{Discussion}

The findings of Graham et al. (2010) point to the effectiveness of a summer family literacy program for young children at-risk for reading difficulties. There were a number of important implications stemming from this previous study. Perhaps the most salient implication centred on the summer learning loss phenomenon. Research on summer learning loss would predict that these children would demonstrate a summer learning loss characterized by significant decreases in their emergent literacy skills such as print and phonological awareness and letter knowledge. However, as a result of participating in the Learning Begins at Home summer literacy program, children did not experience a summer learning loss, and in fact, demonstrated significant gains in their emergent literacy skills. However, although children experienced immediate achievement gains as a result of participating in the program, it was not established in the Graham et al. (2010) study whether such gains would be sustained. More specifically, it was not known whether children would sustain their gains in print and phonological awareness as well as letter-sound correspondence as they entered into their senior kindergarten year. The current study explored this question.

A primary feature of the summer family literacy program adopted in the study was the inclusion of primary caregivers. As indicated in the program description section, primary care- 
givers were an integral component of their child's participation in the program. Each evening caregivers were presented with a workshop where the aim was to explicitly strategize with caregivers about how to most effectively support their children in their literacy activities at home. The purpose of including caregivers followed Timmons' (2008) suggestion that literacy programs are significantly more impactful when caregivers are involved. This suggestion may stem from the common research finding described by O'Connor et al. (1996) that brief children-only literacy interventions are generally insufficient for stable gains for children at-risk for reading difficulties. Following this, the current research team hypothesized that by including primary caregivers the strategies learned in the program would carry forward to the home, thus allowing the short-term gains achieved by the program to be sustained. It was hypothesized that the primary caregivers would continue the literacy program indefinitely within the home environments. Although this study did not directly measure how parents implemented literacy strategies within the home, the posttest II data would act as a proxy measure for how the program was sustained.

The results support this hypothesis. Not only did children sustain the gains achieved in the program, but children in fact continued to increase in their literacy skills relative to agematched normative data. This result was evidenced by the increase of TOPEL measures in the percentile rank scores from posttest I to posttest II. This increase invites the notion that after the completion of the summer literacy program caregivers continued to work with their children to support their literacy needs. Many tutoring-based literacy programs simply focus on the childtutor, one-to-one working relationship. Although one-to-one tutoring programs have been found to be effective, enhancing such programs with a family component enables the skills learned at the tutor session to be practiced and potentially established at home. The findings of the current study support Timmons' (2008) assumption that literacy programs are indeed more effective and stable when caregivers are involved. More generally, establishing effective literacy practices at home will expectantly lead to more systemic gains in literacy achievement throughout the academic careers of children.

The results here hold important implications for research, policy, and practice around supporting young vulnerable learners and their families. First, following the findings of Graham et al. (2010), young children at-risk for reading difficulties are particularly vulnerable during the summer months. As such, it is important that school boards and community agencies consider how to most effectively support vulnerable children over the summer vacation months. The results of this study imply that summer family literacy programs could play an important role in eliminating the summer learning gap. Moreover, including caregivers as an integral component in literacy programs will make a significant impact on how well and how long the gains of a literacy program will be sustained. Furthermore, having the families as an integral part of the intervention empowers the parent and affords them a comfort level to continue to work with his or her child and subsequent children, throughout their school instruction.

There are a number of limitations and future directions associated with the current study. First is the relatively small sample size. The purpose of the current study was to explore the effectiveness of a summer family literacy program in order to specify the most important variables related to developing an effective program. By limiting the sample size, the research team was able to provide one-to-one attention to each participating child - an important tenet of effective remedial instruction. The smaller sample size also enabled the research team to closely monitor the achievement of participating children and their caregivers. However, to further establish the generalizability of such a study, it would be prudent for future research to include a larger sample of participants. The second limitation was the lack of a control group. To firmly establish the 
effectiveness of such a program it would be important to compare the gains of the program group to the achievement levels of a non-program group. A third limitation stems from the fact that children encountered a variety of different educational experiences between when the program ended (posttest I) and posttest II. It was not within the scope of the current study to measure these educational experiences. Future research would benefit from a qualitative account of what children experienced in their kindergarten year. In addition, future research would also benefit from qualitative commentary from caregivers in regards to how they engaged with children after the completion of the intervention program.

Over the past two decades the field of early child education and development has established a solid understanding of the foundational components of emergent literacy. However, it is now important to further this understanding by investigating the contextual variables that impact the effectiveness and stability of effective emergent literacy programs. The aim of this study was to investigate the effectiveness and stability of a summer family emergent literacy program designed for young vulnerable learners. The results of this study indicated that the immediate gains achieved by the summer program could be sustained and even increased over a 6-month period. A contextual variable hypothesized to have contributed to the gains being sustained was the inclusion of caregivers as an integral part of program delivery. The results of this study suggest that including caregivers in the literacy program made a significant impact on how well and how long the gains of a literacy program were sustained. Generally, including caregivers within emergent literacy interventions empowers and affords them a comfort level to continue to work with their child and subsequent children throughout their school instruction.

\section{References}

Cooper, H., Nye, B., Charlton, K., Lindsay, J., \& Greathouse, S. (1996). The effects of summer vacation on achievement test scores: A narrative and meta-analytic review. Review of Educational Research, 66, 227-268.

Desimone, L. (1999). Linking parental involvement with student achievement: Do race and income matter? Journal of Educational Research, 93(1), 11-30.

Dickinson, D., \& McCabe, A. (2001). Bringing it all together: The multiple origins, skills, and environmental supports of early literacy. Learning Disabilities Research \& Practice, 16(4), 186-202.

Doyle, A., Hipfner-Boucher, K., \& Pelletier, J. (2008). Learning Begins at Home (LBH): A research-based family literacy program curriculum. Toronto, ON: Ontario Institute for Studies in Education of the University of Toronto.

Entwisle, D., Alexander, K., \& Olson, L. (2001). Keeping the faucet flowing: Summer learning and home environment. American Educator, 25(3), 10-15.

Graham, A., McNamara, J., \& VanLankveld, J. (2010). Closing the summer learning gap for vulnerable learners: An exploratory study of a summer literacy program for kindergarten children at risk for reading difficulties. Early Child Development and Care, 14 May, 2010 (iFirst).

Heath, S. B. (1982). What no bedtime story means: Narrative skills at home and school. Language and Society, $11(1), 49-76$.

Juel, C., \& Meier, J. (1999). Teaching content and form through balanced instruction. Teaching and Change, $6,182-196$.

Katsiyannis, A. (1991). Extended school year policies: An established necessity. Remedial and Special Education, 12(1), 24-28.

Kim, J. (2006). Effects of a voluntary summer reading intervention on reading achievement: Results from a randomized field trial. Educational Evaluation and Policy Analysis, 28(4), 335-355.

Linver, M., Brooks-Gunn J., \& Kohen, D. (2002). Family processes as pathways from income to young children's development. Developmental Psychology, 38(5), 719-734. 
Lonigan, C., Wagner, R., Torgesen, J., \& Rashotte, C. (2007). Test of preschool early literacy. Austin, TX: PRO-ED.

O'Connor, R. E., Notari-Syverson, A., \& Vadasy, P. (1996). Ladders to literacy: The effects of teacher-led phonological activities for kindergarten children with and without disabilities. Exceptional Children, 63, 117-130.

Stastistics Canada. (2007). Income of Canadians. Retrieved from http://www.statcan.gc.ca/daily-quotidien /090603/dq090603a-eng.htm

Teale, W. H., \& Sulzby, E. (1986). Emergent literacy: Writing and reading. Santa Barbara, CA: Greenwood Publishing Group.

Timmons, V. (2008). Challenges in researching family literacy programs. Canadian Psychology, 49(2), 96102.

Vervaeke S. L., McNamara, J. K., \& Scissons, M. (2007). Kindergarten screening for reading disabilities. Journal of Applied Research on Learning, 1(1), 1-19.

\section{Authors' Notes}

Correspondence concerning this article should be addressed to John McNamara, Department of Child and Youth Studies, Brock University, St. Catharines, ON L2S 3A1.

E-mail: jmcnamara@brocku.ca

The authors would like to thanks Janette Pelletier for the use of LBH and her input into the project. The authors would also like to acknowledge the Niagara Prosperity Initiative for a grant making this work possible. 